\title{
Effects of acetylcholine and noradrenalin on action potentials of isolated rabbit sinoatrial and atrial myocytes
}

\author{
Arie O. Verkerk ${ }^{1 \dagger}$, Guillaume S. C. Geuzebroek ${ }^{2 \dagger}$, Marieke W. Veldkamp ${ }^{2}$ and Ronald Wilders ${ }^{1 *}$ \\ ${ }^{1}$ Department of Anatomy, Embryology and Physiology, Academic Medical Center, University of Amsterdam, Amsterdam, Netherlands \\ 2 Department of Experimental Cardiology, Academic Medical Center, University of Amsterdam, Amsterdam, Netherlands
}

Edited by:

Craig Doupnik, University of South

Florida College of Medicine, USA

Reviewed by:

T. Alexander Quinn, University of Oxford, UK

Rob Gourdie, Medical University of South Carolina, USA

\section{*Correspondence:}

Ronald Wilders, Department of

Anatomy, Embryology and Physiology, Academic Medical Center, University of Amsterdam, Meibergdreef 15,

Amsterdam, Netherlands.

e-mail: r.wilders@amc.uva.nl

${ }^{\dagger}$ Arie O. Verkerk and Guillaume S. C. Geuzebroek have contributed equally to this work.
The autonomic nervous system controls heart rate and contractility through sympathetic and parasympathetic inputs to the cardiac tissue, with acetylcholine (ACh) and noradrenalin (NA) as the chemical transmitters. In recent years, it has become clear that specific Regulators of $G$ protein Signaling proteins (RGS proteins) suppress muscarinic sensitivity and parasympathetic tone, identifying RGS proteins as intriguing potential therapeutic targets. In the present study, we have identified the effects of $1 \mu \mathrm{M}$ ACh and $1 \mu \mathrm{M}$ NA on the intrinsic action potentials of sinoatrial (SA) nodal and atrial myocytes. Single cells were enzymatically isolated from the SA node or from the left atrium of rabbit hearts. Action potentials were recorded using the amphotericin-perforated patch-clamp technique in the absence and presence of ACh, NA, or a combination of both. In SA nodal myocytes, ACh increased cycle length and decreased diastolic depolarization rate, whereas NA decreased cycle length and increased diastolic depolarization rate. Both ACh and NA increased maximum upstroke velocity. Furthermore, ACh hyperpolarized the maximum diastolic potential. In atrial myocytes stimulated at $2 \mathrm{~Hz}$, both ACh and NA hyperpolarized the maximum diastolic potential, increased the action potential amplitude, and increased the maximum upstroke velocity. Action potential duration at 50 and $90 \%$ repolarization was decreased by ACh, but increased by NA. The effects of both ACh and NA on action potential duration showed a dose dependence in the range of 1-1000 nM, while a clear-cut frequency dependence in the range of $1-4 \mathrm{~Hz}$ was absent. Intermediate results were obtained in the combined presence of ACh and NA in both SA nodal and atrial myocytes. Our data uncover the extent to which SA nodal and atrial action potentials are intrinsically dependent on ACh, NA, or a combination of both and may thus guide further experiments with RGS proteins.

Keywords: cardiac myocytes, sinoatrial node, left atrium, patch-clamp, action potentials, pacemaker activity, acetylcholine, noradrenalin

\section{INTRODUCTION}

Electrical activity of cardiac cells is modulated through adrenergic and muscarinic stimulation. The intrinsic pacemaker activity of sinoatrial (SA) nodal cells is accelerated upon noradrenalinmediated stimulation of the adrenergic $\beta$-receptors and decelerated by acetylcholine-mediated stimulation of the muscarinic $\mathrm{M}_{2}$-receptors. Both are $\mathrm{G}$ protein-coupled receptors (GPCRs). In recent years, it has become widely appreciated that GPCR signaling in SA nodal pacemaker cells is much more complex than activation of a single membrane current, e.g., activation of the acetylcholine-activated outward potassium current $I_{\mathrm{K}, \mathrm{ACh}}$ in response to a release of acetylcholine (Maltsev and Lakatta, 2010; van Borren et al., 2010). If noradrenalin binds to its $\beta$-receptor, it activates adenylyl cyclases through its stimulatory $G$ protein $\alpha$-subunit $\left(\mathrm{G} \alpha_{\mathrm{s}}\right)$ and thus increases cAMP and protein kinase $\mathrm{A}$ levels. Similarly, if acetylcholine binds to its receptor, it decreases these levels through its inhibitory $\mathrm{G}$ protein $\alpha$-subunit $\left(\mathrm{G} \alpha_{i}\right)$. In addition, acetylcholine exerts its effects through a $G \beta \gamma$-mediated activation of the aforementioned $I_{\mathrm{K}, \mathrm{ACh}}$. Noradrenalin accelerates the interdependent "membrane clock" and "calcium clock" of the pacemaker cell, whereas these are decelerated by acetylcholine (Maltsev and Lakatta, 2010; van Borren et al., 2010).

It should be kept in mind that noradrenalin not only stimulates the $\mathrm{G}_{\mathrm{s}}$-coupled $\beta_{1}-\beta_{3}$ adrenoceptors but also the $\mathrm{G}_{\mathrm{q}}$-coupled $\alpha_{1}$ and $\mathrm{G}_{\mathrm{i}}$-coupled $\alpha_{2}$ adrenoceptors, and that acetylcholine not only stimulates the $\mathrm{G}_{\mathrm{i}}$-coupled $\mathrm{M}_{2}$-receptor but also the other muscarinic receptors, including the $\mathrm{G}_{\mathrm{q}}$-coupled $\mathrm{M}_{3}$-receptor, which is functionally present in the murine sinoatrial node (Abramochkin et al., 2012). Adding to this complexity, it has also become clear that GPCR signaling is not a simple linear pathway of receptor, $G$ protein, and effector. Signaling may be modulated by $G$ protein-binding partners, specifically by members of the family of Regulators of G protein Signaling proteins (RGS proteins). RGS proteins may suppress muscarinic sensitivity and parasympathetic tone and thus affect heart rate and susceptibility to atrial fibrillation. If neuronally expressed, RGS proteins may also affect both sympathetic and parasympathetic output in addition to their direct effects in cardiac myocytes. The function of RGS proteins and their potential as therapeutic targets have recently received attention in several reviews (Sjögren and Neubig, 2010; Sjögren 
et al., 2010; Kimple et al., 2011; Tilley, 2011; Zhang and Mende, 2011)

Studies with transgenic mice have underlined the important role of specific RGS proteins in the heart. In RGS4 knockout $\left(\mathrm{RGS4}^{-1-}\right)$ mice, Cifelli et al. (2008) observed enhanced heart rate responses to the cholinergic agonist carbamylcholine chloride (carbachol), both in intact animals and in isolated hearts. In line with these observations, the beating frequency of isolated SA nodal myocytes, as assessed with the perforated patch-clamp technique at room temperature, did not differ between $\mathrm{RGS}^{-1-}$ and control under basal conditions, but showed an enhanced susceptibility to carbachol. This enhanced susceptibility was associated with a reduced desensitization and a slower deactivation of $I_{\mathrm{K}, \mathrm{ACh}}$ in $\mathrm{RGS}^{-1-}$ myocytes. Similar observations were made by Yang et al. (2010) with RGS6 knockout (RGS6 ${ }^{-1-}$ ) mice. An enhanced bradycardia in response to carbachol was found in intact animals, in perfused hearts, and in isolated SA nodal myocytes. Whole-cell patch-clamp recordings from cultured RGS6 ${ }^{-1-}$ atrial myocytes revealed a significant reduction in the time course of activation and deactivation of $I_{\mathrm{K}, \mathrm{ACh}}$ as well as the extent of its desensitization. Of note, perfused hearts from $\mathrm{RGS}^{-1-}$ mice showed a normal chronotropic response to the $\beta$-adrenergic agonist isoproterenol. Posokhova et al. (2010) also studied heart rate and $I_{\mathrm{K}, \mathrm{ACh}}$ in $\mathrm{RGS6}^{-1-}$ mice. In intact animals, they found a mild resting bradycardia and an enhanced bradycardic effect of carbachol. In whole-cell patch-clamp recordings from adult SA nodal and cultured neonatal atrial myocytes, $I_{\mathrm{K}, \mathrm{ACh}}$ showed a slowed deactivation rate, which was also observed in case of deletion of the type $5 \mathrm{G}$ protein $\beta$ subunit (G $\beta 5$ ), indicating that the effect is mediated by the RGS6/G $\beta 5$ complex rather than by RGS6 itself.

The modulatory role of endogenous RGS proteins in the muscarinic and adrenergic control of heart rate had already been demonstrated in studies by Fu et al. (2006, 2007). Furthermore, Bender et al. (2008) had shown that the $\beta$-adrenergic effects on deactivation of $I_{\mathrm{K}, \mathrm{ACh}}$, i.e., a marked increase in the time constant of its deactivation, are mediated via RGS10 in rat atrial myocytes. Also, Tuomi et al. (2009) had found that atrial effective refractory periods were smaller in RGS2 knockout mice, likely due to enhanced muscarinic $\mathrm{M}_{3}$-receptor activity, and that these mice had an enhanced susceptibility to pacing-induced atrial tachycardia and fibrillation.

Given the potential role of RGS proteins as therapeutic means for modulating heart rate and atrial effective refractory period, it is important to know the effects of noradrenalin and acetylcholine on the intrinsic electrical activity of cardiac myocytes, specifically SA nodal and atrial myocytes. Over a period of decades, studies at the whole-heart and tissue levels have provided us with important data regarding the effects of sympathetic and parasympathetic stimulation and their interaction (e.g., Toda and Shimamoto, 1968; Grodner et al., 1970; Levy, 1971; Mackaay et al., 1980; Boyett et al., 1995; Brack et al., 2004). However, data on action potential configuration from isolated myocytes are not abundant, particularly with the second-messenger systems intact. In the present study, we used the amphotericin-perforated patch-clamp technique to record action potentials from isolated rabbit SA nodal and left atrial myocytes and assess the response to noradrenalin, acetylcholine, or a combination thereof, thus providing data that may prove useful in the development of RGS protein based therapeutical means.

\section{MATERIALS AND METHODS CELL PREPARATION}

All experiments were carried out in accordance with guidelines of the local institutional animal care and use committee. In addition, the investigation complied with the Guide for the Care and Use of Laboratory Animals published by the US National Institutes of Health (NIH Publication No. 85-23, revised 1996). Both SA nodal and atrial cells were isolated from hearts of male New Zealand White rabbits of 4 months old.

Single SA nodal cells were enzymatically isolated from the entire SA nodal region as described previously (Verkerk et al., 2009). Single atrial cells were isolated by enzymatic dissociation from the left atrium using the same protocol as described previously for the isolation of ventricular myocytes (Den Ruijter et al., 2010), with the adaptation that the enzymatic solution was complemented with $6.6 \mu \mathrm{g} / \mathrm{mL}$ protease. Small aliquots of either SA nodal or atrial cell suspension were put in a recording chamber on the stage of an inverted microscope. Cells were allowed to adhere for 5 min after which superfusion with Tyrode's solution was started. Tyrode's solution had a temperature of $36 \pm 0.2^{\circ} \mathrm{C}$ and contained (in $\mathrm{mM}$ ): $\mathrm{NaCl} 140, \mathrm{KCl} 5.4, \mathrm{CaCl}_{2} 1.8, \mathrm{MgCl}_{2} 1.0$, glucose 5.5, and HEPES 5.0; pH was set to 7.4 with $\mathrm{NaOH}$. Spindle and elongated spindle-like cells displaying regular contractions were selected for recordings from SA nodal myocytes. Intrinsically quiescent rod-shaped cross-striated myocytes with a smooth surface were selected for recording from atrial myocytes.

\section{PATCH-CLAMP EXPERIMENTS}

Action potentials were recorded by the amphotericin-perforated patch-clamp technique using an Axopatch 200B amplifier (Molecular Devices, Sunnyvale, CA, USA). SA nodal action potentials were low-pass filtered (cut-off frequency $1 \mathrm{kHz}$ ) and digitized at $2 \mathrm{kHz}$; atrial action potentials at 5 and $40 \mathrm{kHz}$, respectively. Potentials were corrected for the estimated liquid junction potential (Barry and Lynch, 1991). Data acquisition and analysis were accomplished using custom software. For recording from SA nodal myocytes, pipettes (borosilicate glass; resistance 2-3M $\Omega$ ) were heat polished and filled with solution containing (in $\mathrm{mM}$ ): Kgluc 125, $\mathrm{KCl} 20, \mathrm{NaCl} 10$, amphotericin-B 0.22 , and HEPES 10; $\mathrm{pH}$ was set to 7.2 with $\mathrm{KOH}$. For recording from atrial myocytes, the pipette solution contained (in mM): K-gluc 110, $\mathrm{KCl} 30, \mathrm{NaCl}$ $5, \mathrm{MgCl}_{2} 1$, amphotericin-B 0.22 , and HEPES 10 ; $\mathrm{pH}$ was set to 7.28 with $\mathrm{KOH}$. Action potentials in atrial cells were elicited at $1-$ $4 \mathrm{~Hz}$ by 2 -ms, $\approx 1.5 \times$ threshold current pulses through the patch pipette.

Action potentials were characterized by duration at 20,50, and $90 \%$ repolarization $\left(\mathrm{APD}_{20}, \mathrm{APD}_{50}\right.$, and $\mathrm{APD}_{90}$, respectively), maximum diastolic potential (MDP), action potential amplitude, maximum upstroke velocity, and, in case of SA nodal myocytes, cycle length and diastolic depolarization rate measured over the 50 -ms time interval starting at MDP $+1 \mathrm{mV}$. Parameter values obtained from 10 consecutive action potentials were averaged. Action potentials were measured in the absence and presence of noradrenalin, acetylcholine, or a combination of both in the same 
myocyte. In case of atrial myocytes, the myocyte was stimulated at a frequency of $2 \mathrm{~Hz}$, unless otherwise stated. In order to obtain steady-state conditions, action potential recordings were started 5 min after the addition of noradrenalin or acetylcholine to the Tyrode's solution.

\section{STATISTICS}

Data are presented as mean \pm SEM. Paired comparisons were made using a paired $t$-test. Group comparisons were made using either an unpaired $t$-test or one-way ANOVA with the Holm-Sidak post hoc test. Frequency dependence and dose dependence were assessed with the Friedman repeated measures ANOVA on ranks, followed by pairwise comparisons with the Student-NewmanKeuls post hoc test. $P<0.05$ defined statistical significance.

\section{RESULTS \\ ACTION POTENTIAL CHARACTERISTICS OF SA NODAL AND ATRIAL MYOCYTES}

First, we characterized the action potentials of the SA nodal and left atrial myocytes that we used for our study. SA nodal cells were spontaneously active, while atrial cells were quiescent. In atrial cells, action potentials could be elicited by current pulses through the patch pipette. Figure 1A shows typical spontaneous action potentials of an SA nodal myocyte as well as typical action potentials recorded from an atrial myocyte that was stimulated at $3 \mathrm{~Hz}$, i.e., with a cycle length similar to that of the SA nodal myocyte. Average action potential parameters are summarized in Figure 1B. All parameters, except $\mathrm{APD}_{90}$, differed significantly between both cell types. Atrial myocytes had a stable resting membrane potential of $-79.2 \pm 1.1 \mathrm{mV}(n=12)$, while SA nodal cells showed a spontaneous diastolic depolarization with a maximum diastolic potential of $-63.5 \pm 1.7 \mathrm{mV}$ $(n=12)$. In SA nodal cells, this diastolic depolarization resulted in pacemaker activity with an intrinsic cycle length of $302 \pm 10 \mathrm{~ms}$. In SA nodal cells, the maximum upstroke velocity was typically low $(6.6 \pm 1.1 \mathrm{~V} / \mathrm{s})$ as opposed to atrial myocytes $(297 \pm 39 \mathrm{~V} / \mathrm{s})$. In both cell types, action potentials overshot the zero potential value, but the APA was higher in atrial myocytes. Action potentials of atrial myocytes repolarized earlier and faster, resulting in shorter $\mathrm{APD}_{20}$ and $\mathrm{APD}_{50}$; however, $\mathrm{APD}_{90}$ did not differ significantly. Atrial action potentials showed a frequency dependence in maximum upstroke velocity, $\mathrm{APD}_{20}$ and $\mathrm{APD}_{50}$. Both $\mathrm{APD}_{20}$ and $\mathrm{APD}_{50}$ increased with an increase in stimulus frequency, whereas maximum upstroke velocity tended to decrease with an increase in frequency (Figure 1C).

\section{EFFECTS OF NORADRENALIN AND ACETYLCHOLINE ON SA NODAL ACTION POTENTIALS}

Next, we assessed the effects of noradrenalin, acetylcholine, or a combination thereof on the action potentials of our SA nodal myocytes. As illustrated in Figure 2A, application of noradrenalin resulted in an increase in the spontaneous beating frequency, associated with an increase in the diastolic depolarization rate without any striking differences in other action potential parameters. Application of acetylcholine, on the other hand, resulted in a clear hyperpolarization of the maximum diastolic potential, a decrease in the diastolic depolarization rate and a dramatic increase in cycle length (Figure 2B). If acetylcholine was applied

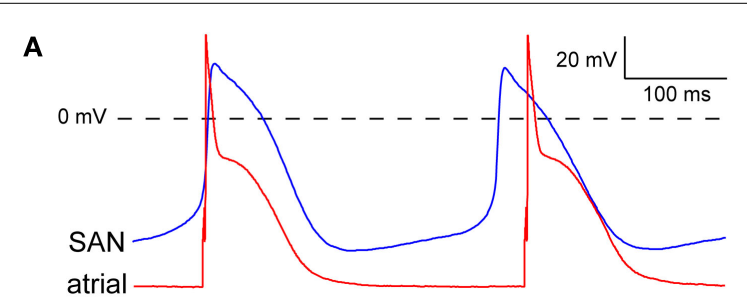

B
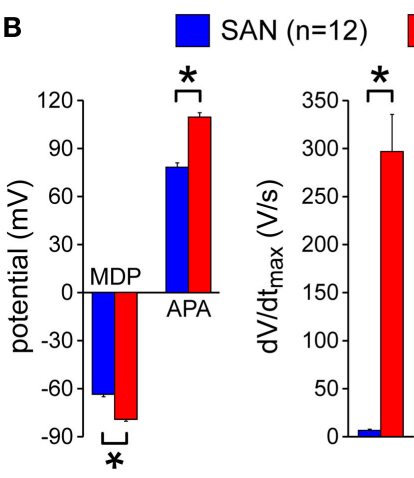

atrial $(n=12)$

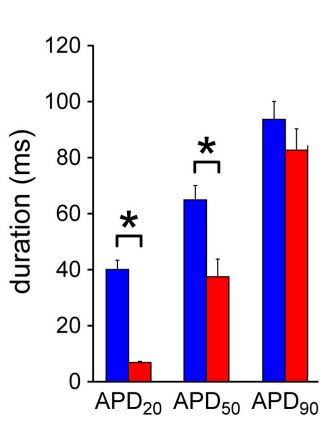

FIGURE 1 | Action potential characteristics of isolated rabbit SA nodal (SAN) and atrial myocytes. (A) Typical action potentials of an isolated SA nodal myocyte and an atrial myocyte. The atrial myocyte was stimulated at $3 \mathrm{~Hz}$. (B) Action potential parameters of SA nodal and atrial myocytes, including maximum diastolic potential (MDP), action potential amplitude (APA), maximum upstroke velocity $\left(d V / d t_{\text {max }}\right)$, and action
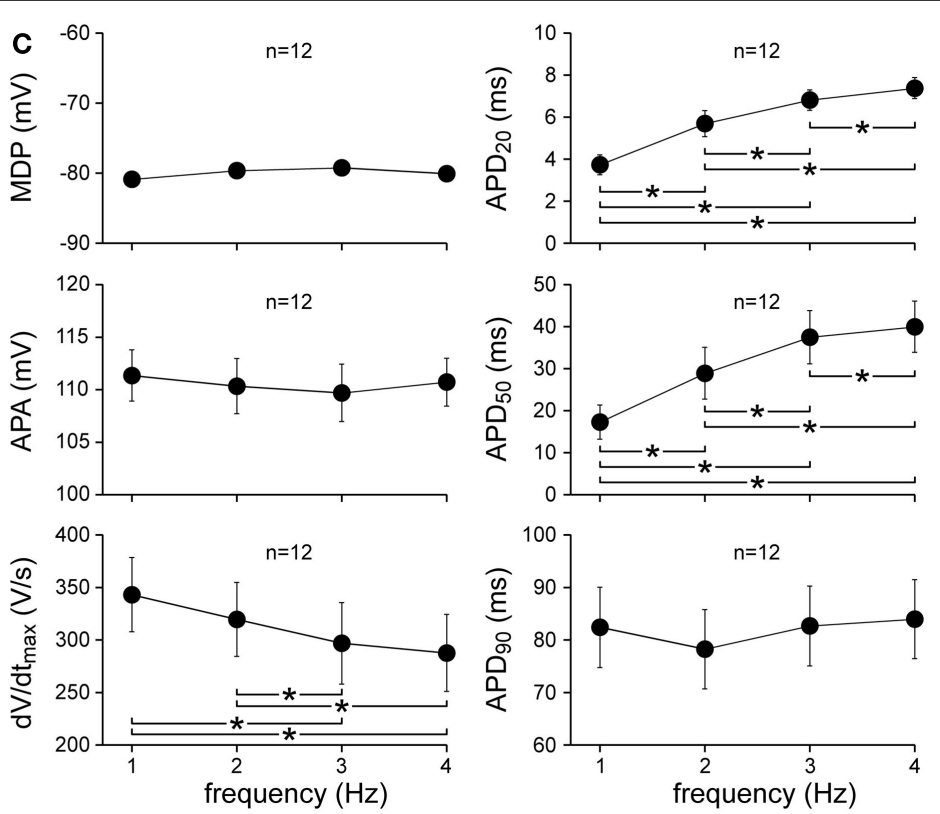

potential duration at 20,50, and $90 \%$ repolarization $\left(\mathrm{APD}_{20}, \mathrm{APD}_{50}\right.$, and $A P D_{90}$, respectively). The atrial myocytes were stimulated at $3 \mathrm{~Hz}$. Asterisks indicate significant differences between both cell types. (C) Frequency dependence of the action potential parameters of the atrial myocytes. Asterisks indicate significant differences between stimulus frequencies. 


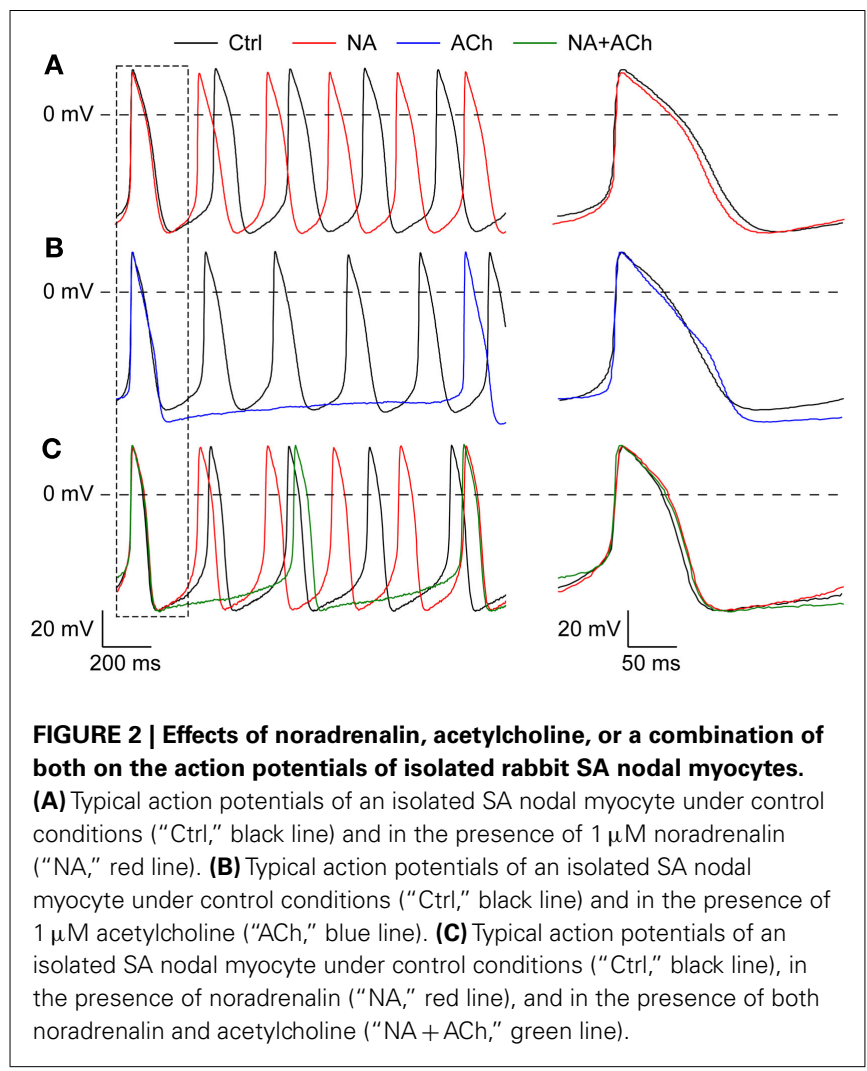

in the presence of noradrenalin, there was no substantial hyperpolarization of the maximum diastolic potential and the increase in cycle length was less prominent (Figure 2C).

Figure 3 summarizes the effects on action potential parameters for a total of 13 cells. These data confirm the aforementioned effects on cycle length (Figure 3A), diastolic depolarization rate (Figure 3B), and maximum diastolic potential (Figure 3C). In addition, Figure 3 shows that both noradrenalin and acetylcholine caused an increase in maximum upstroke velocity, which was larger in case of acetylcholine (Figure 3E). Figure 3 may suggest that acetylcholine increases action potential amplitude (Figure 3D) and action potential duration (Figures 3F-H), but it should be noted that these data are not statistically significant. According to Figure 3, and also Figure 2C, intermediate results were obtained in the combined presence of noradrenalin and acetylcholine, but it should be noted that these observations are based on data from only one cell, as emphasized by the use of "bleached" bars for "NA + ACh" in Figure 3.

\section{EFFECTS OF NORADRENALIN AND ACETYLCHOLINE ON ATRIAL ACTION POTENTIALS}

We also assessed the effects of noradrenalin, acetylcholine, or a combination thereof on the action potentials of our atrial myocytes. The results are shown in Figures 4-7.

As illustrated in Figure 4A, application of noradrenalin resulted in a slight hyperpolarization of the maximum diastolic potential. The same was found for acetylcholine (Figure 4B), but not so much for the combination of noradrenalin and acetylcholine (Figure 4C). In all cases, i.e., application of noradrenalin,

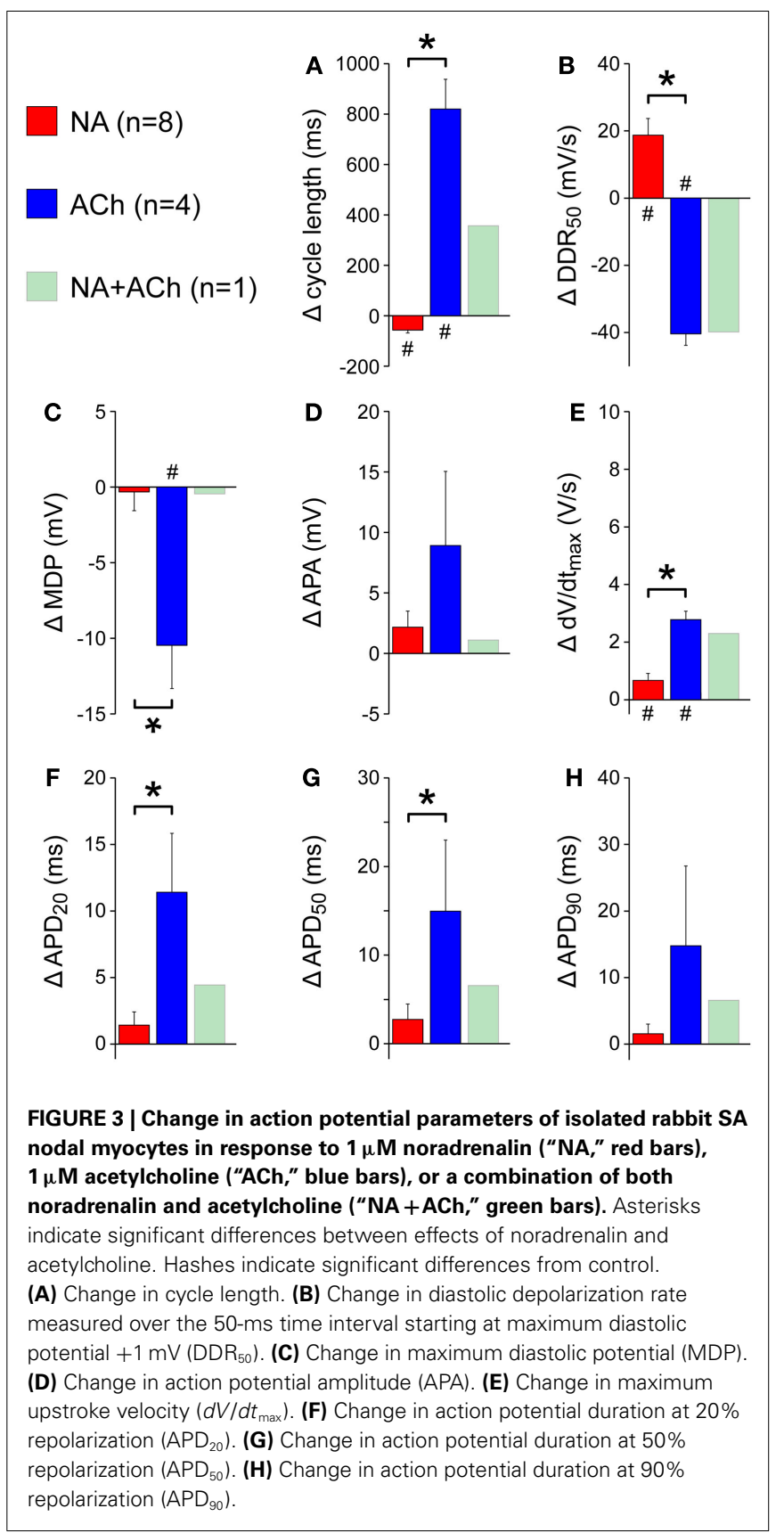

acetylcholine, or a combination thereof, the action potential amplitude was increased. Effects on action potential duration differed between noradrenalin and acetylcholine, with an increase in case of noradrenalin and a decrease for acetylcholine (Figures 4A,B) and a less pronounced effect for the combination of noradrenalin and acetylcholine (Figure 4C).

Figure 5 summarizes the effects on action potential parameters for a total of 23 cells. As already observed in the typical examples of Figure 4, there is a slight hyperpolarization of the maximum diastolic potential (Figure 5A) and an increase in action potential amplitude (Figure 5B). Also, under all conditions there is an increase in maximum upstroke velocity (Figure 5C). The effects 


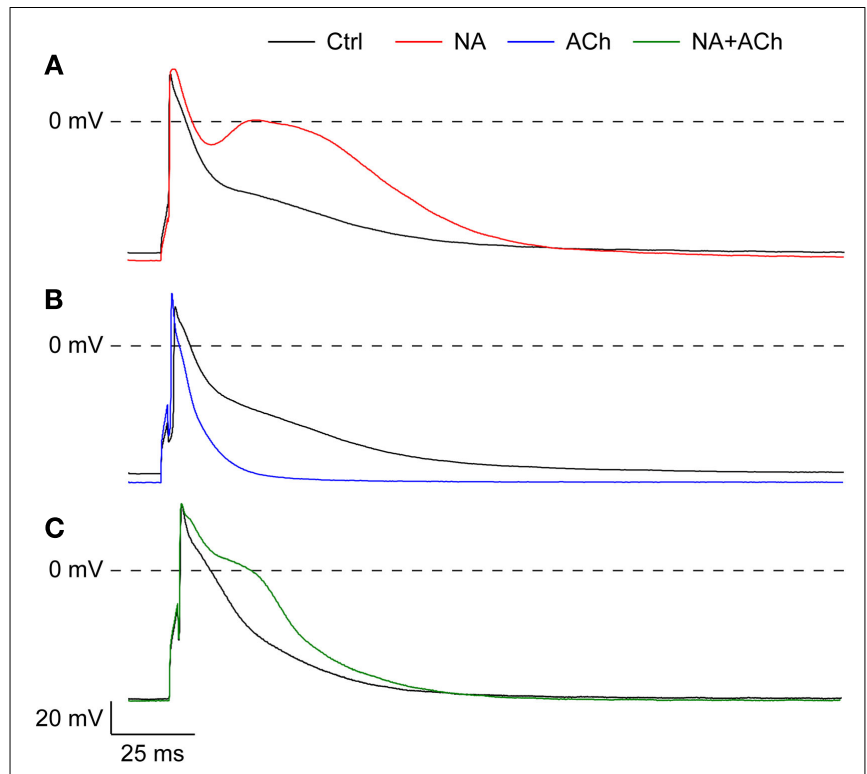

FIGURE 4 | Effects of noradrenalin, acetylcholine, or a combination of both on the action potentials of isolated rabbit left atrial myocytes. (A) Typical action potentials of an isolated atrial myocyte under control conditions ("Ctrl," black line) and in the presence of $1 \mu \mathrm{M}$ noradrenalin ("NA," red line). (B) Typical action potentials of an isolated atrial myocyte under control conditions ("Ctrl," black line) and in the presence of $1 \mu \mathrm{M}$ acetylcholine ("ACh," blue line). (C) Typical action potentials of an atrial myocyte under control conditions ("Ctrl," black line) and in the presence of both noradrenalin and acetylcholine ("NA+ACh," green line).

on $\mathrm{APD}_{50}$ and $\mathrm{APD}_{90}$ are different between the three conditions, with a decrease in case of acetylcholine, an increase in case of noradrenalin and a smaller, but still significant increase in case of acetylcholine combined with noradrenalin (Figures 5E,F).

In addition to the experiments of Figures 4 and 5, in which the cells were stimulated at $2 \mathrm{~Hz}$, we carried out experiments in which we varied the stimulation frequency over the range of $1-4 \mathrm{~Hz}$. The data, obtained from a total of 12 cells, did not reveal a clear-cut frequency dependence in the effects of acetylcholine or noradrenalin on action potential duration (Figure 6). Data obtained in the combined presence of noradrenalin and acetylcholine are from only two cells and therefore appear "grayed out" in Figure 6.

The above data were obtained with noradrenalin and acetylcholine concentrations of $1 \mu \mathrm{M}(1000 \mathrm{nM})$. In a total of five cells, we varied these concentrations over the range of $1-1000 \mathrm{nM}$. The effects on action potential duration showed a dose dependence, in particular for $\mathrm{APD}_{50}$, with considerably smaller effects at $1 \mathrm{nM}$ than at $1 \mu \mathrm{M}$ (Figure 7 ). However, it should be noted that the data with acetylcholine are from one cell, as are the data in the combined presence of noradrenalin and acetylcholine. These data therefore appear "grayed out" in Figure 7.

\section{DISCUSSION}

In the present study, we have assessed the effects of noradrenalin, acetylcholine, or a combination thereof on the action potential configuration of rabbit SA nodal and left atrial myocytes. Action potentials were recorded under close-to-physiological conditions.

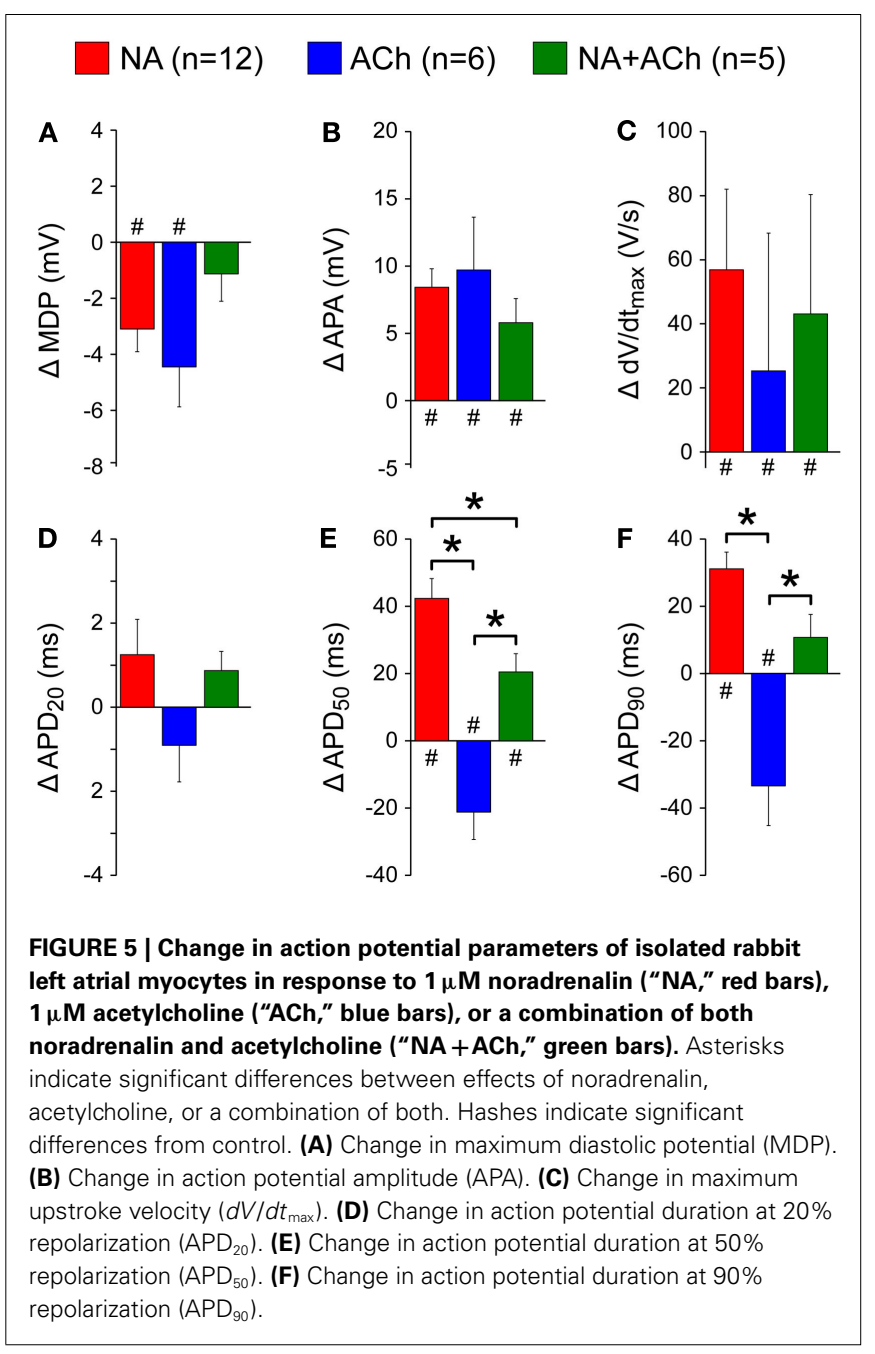

The temperature of the bath solution was maintained at $36^{\circ} \mathrm{C}$ and the amphotericin-perforated patch-clamp technique was used to minimize intracellular dialysis, thus maintaining the integrity of second-messenger systems. To the best of our knowledge, the present study is the first in which the effects of noradrenalin, acetylcholine, or a combination thereof on the action potential configuration of isolated sinoatrial and atrial myocytes has been tested in detail under such close-to-physiological conditions.

As detailed in Figure 1, our SA nodal and atrial myocytes showed clearly distinct action potential characteristics. We obtained our myocytes from rabbit, which is a widely used animal model in the field of cardiac cellular electrophysiology. In many respects, human action potential morphology is better resembled by rabbit than by mouse (Brunner et al., 2008). Yet, one should be aware that there may be species differences in the underlying mechanisms, as there are, e.g., in calcium handling and adenylate cyclase activity between mouse and man (Jweied et al., 2007).

\section{EFFECTS OF NORADRENALIN AND ACETYLCHOLINE ON SA NODAL ACTION POTENTIALS}

The beating rate of our SA nodal cells increases upon application of noradrenalin and decreases upon application of acetylcholine 

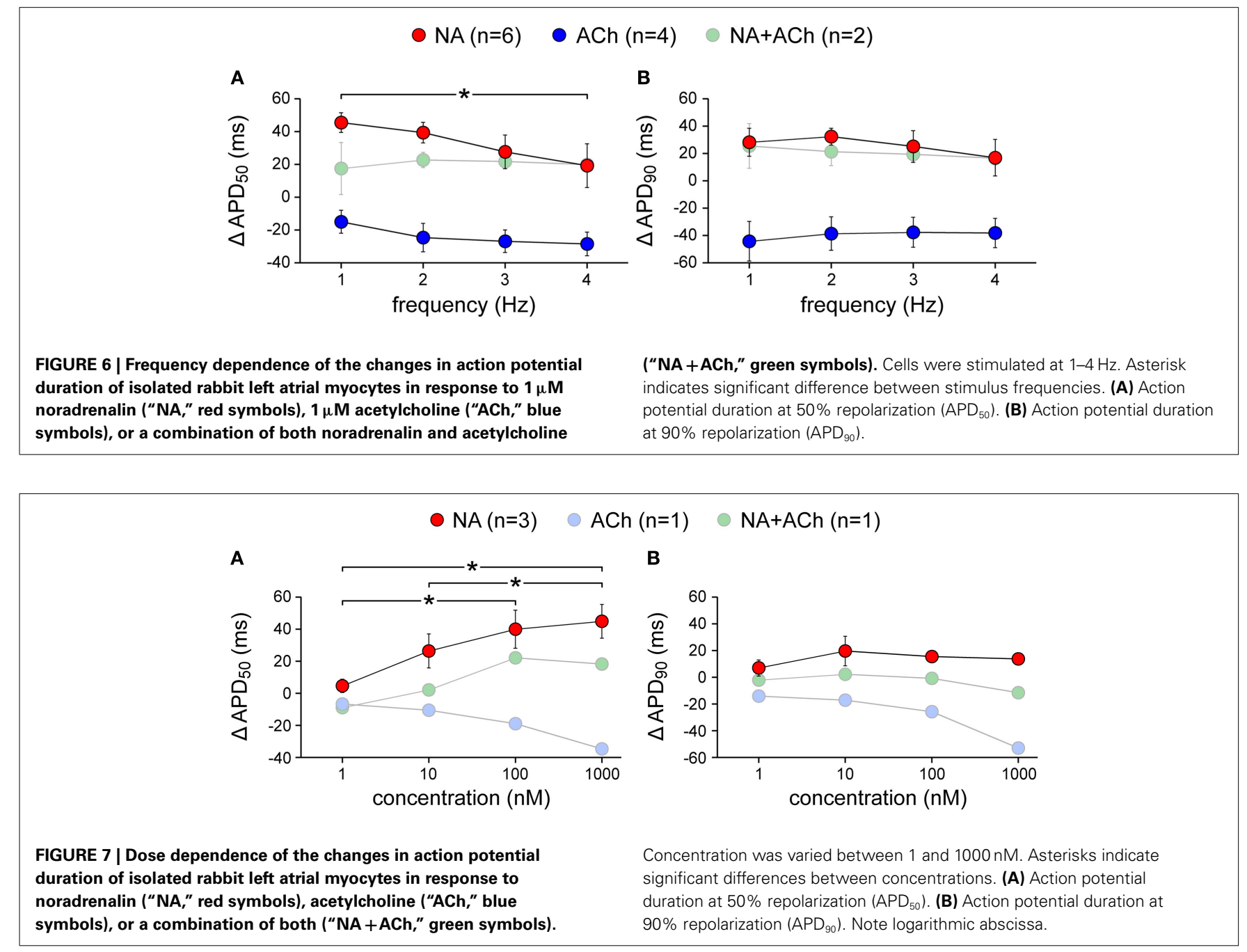

(Figures 2A,B and 3A), which is associated with an increase and a decrease in the rate of diastolic depolarization, respectively (Figure 3B). It is tempting to explain this change in depolarization rate by a cAMP-mediated upregulation or downregulation of the hyperpolarization-activated "pacemaker current" or "funny current" $I_{\mathrm{f}}$ (DiFrancesco, 1995). However, one should be cautious when drawing conclusions regarding underlying mechanisms from changes in action potentials. This may be illustrated by the increase in maximum upstroke velocity that is observed in response to noradrenalin as well as acetylcholine (Figure 3E). In case of noradrenalin, this increase may well result from an upregulation of the L-type calcium current $I_{\mathrm{Ca}, \mathrm{L}}$ (Hagiwara et al., 1988), but in case of acetylcholine the even larger increase may be the effect of less voltage-dependent inactivation of $I_{\mathrm{Ca}, \mathrm{L}}$ due to the larger recovery time between consecutive upstrokes and less calcium-dependent inactivation of $I_{\mathrm{Ca}, \mathrm{L}}$ due to the smaller calcium transients (van Borren et al., 2010). Additionally, the activation of a small number of fast sodium channels may have contributed to the increase in maximum upstroke velocity as a result of the acetylcholine-induced hyperpolarization of the maximum diastolic potential which results in incomplete voltage-dependent inactivation of these channels (Veldkamp et al., 2003). A full exploration of the autonomic modulation of the complex dynamic interactions of voltage- and calcium-dependent processes within the SA nodal pacemaker cell may require in silico experiments (Maltsev and Lakatta, 2010). Such experiments have already proven useful in a computer simulation study of the autonomic modulation of the electrical activity of bullfrog atrial myocytes (Shumaker et al., 1991). Figures 3F-H suggest an increase in action potential duration in response to acetylcholine, but this may reflect, at least in part, the hyperpolarization of the maximum diastolic potential (Figure 3C) rather than a "true" increase in action potential duration. This hyperpolarization can be readily explained by the activation of $I_{\mathrm{K}, \mathrm{ACh}}$ (van Borren et al., 2010).

A reduction in beating frequency as well as a hyperpolarization of the maximum diastolic potential was also reported for SA nodal myocytes isolated from wild-type mice in response to carbachol (Cifelli et al., 2008). These effects were both larger for myocytes from RGS4 ${ }^{-1-}$ mice. In the top panel of their Online Figure 5, Yang et al. (2010) show "representative recordings of spontaneous action potential firing in SA nodal myocytes isolated from wild-type mice." With an increase in cycle length, a decrease in diastolic 
depolarization rate, a hyperpolarization of the maximum diastolic potential and an increase in action potential amplitude, the changes in action potential configuration in response to carbachol are consistent with our data for rabbit SA nodal myocytes in response to acetylcholine (Figure 3).

\section{EFFECTS OF NORADRENALIN AND ACETYLCHOLINE ON ATRIAL ACTION POTENTIALS}

In our atrial myocytes, we found a hyperpolarization of the maximum diastolic potential (or "resting" membrane potential) in response to acetylcholine (Figure 5A), as we did in our SA nodal myocytes (Figure 3C). However, in contrast to our SA nodal myocytes, such hyperpolarization was also observed in response to noradrenalin. This may be explained by the $\beta$-adrenergic activation of $I_{\mathrm{K}, \mathrm{ACh}}$ in atrial myocytes (Sorota et al., 1999) and by the $\beta$-adrenergic stimulation of the atrial-specific potassium current $I_{\mathrm{KH}}$ (Ehrlich et al., 2004; Yeh et al., 2007). Furthermore, we found an increase in action potential amplitude and, as in our SA nodal myocytes, an increase in maximum upstroke velocity both in response to noradrenalin and in response to acetylcholine (Figures 5B,C). This may be explained by an increase in the fast sodium current, which is responsible for the fast upstroke in atrial cells, due to the more negative maximum diastolic potential and thus larger availability of fast sodium channels (less voltagedependent inactivation). On the other hand, increased intracellular calcium levels in response to noradrenalin may have inhibitory effects on these sodium channels (Casini et al., 2009), but such effects are not apparent in our current data.

Action potential duration is increased in response to noradrenalin and decreased in response to acetylcholine, with more or less additive effects if both noradrenalin and acetylcholine are present (Figures 5D-F). The shortening of the action potential in response to acetylcholine is in line with data from literature (Koumi et al., 1995; Patterson et al., 2008) and may be attributed to the activation of $I_{\mathrm{K}, \mathrm{ACh}}$. Of note, acetylcholine does not inhibit the L-type calcium current of atrial myocytes under basal conditions, in contrast to that of SA nodal myocytes (Petit-Jacques et al., 1993).

The increase in action potential duration in response to noradrenalin (Figures 5D-F) may be attributed to the increase in $I_{\mathrm{Ca}, \mathrm{L}}$ in response to $\beta$-adrenergic stimulation (Bean, 1985; Dun et al., 2003), which would then be sufficiently large to counteract the action potential shortening effects of the aforementioned $\beta$-adrenergic activation of $I_{\mathrm{K}, \mathrm{ACh}}$ and $I_{\mathrm{KH}}$. However, Yeh et al. (2007) observed a prominent decrease in action potential duration in a canine left atrial tissue preparation in response to specific $\beta$-adrenergic stimulation by isoproterenol (isoprenaline, $5 \mu \mathrm{M}$ ). This suggests that the $\alpha$-adrenergic action of noradrenalin is essential for the increase in action potential duration that we observed in our experiments. A clear increase in action potential duration in response to the selective $\alpha_{1}$-adrenergic receptor agonist phenylephrine $(100 \mu \mathrm{M})$ has been observed in left, but not right, atrial preparations from rabbit heart (Jahnel et al., 1992). In isolated rat atria, Northover (1994) also observed a significant increase in action potential duration in response to phenylephrine $(50 \mu \mathrm{M})$, whereas the effects of isoproterenol $(0.5 \mu \mathrm{M})$ were small and rather variable. In contrast, phenylephrine $(100 \mu \mathrm{M})$ only had a minor effect on action potential duration in the experiments by Yeh et al. (2007). The apparent discrepancies in experimental results may be explained by species- and tissue-dependent differences and/or by differences in cAMP levels due to differences in basal adenylyl cyclase activity (Méry et al., 1997; Harvey and Belevych, 2003). Furthermore, a dose dependence in the effects of isoproterenol and phenylephrine on the action potential and the underlying transmembrane currents may play a role (Shumaker et al., 1991).

The data on action potential duration of Figure 5 were obtained at a stimulus frequency of $2 \mathrm{~Hz}$. Figure $\mathbf{6}$ demonstrates that similar effects were obtained at other frequencies in the range of $1-4 \mathrm{~Hz}$, without a clear-cut frequency dependence, although the increase in $\mathrm{APD}_{50}$ at $1 \mathrm{~Hz}$ in the presence of noradrenalin is significantly different from that at $4 \mathrm{~Hz}$. The data at $2 \mathrm{~Hz}$ of Figure $6 \mathrm{~A}$ are in line with the data of Figure 5E. Also, there is consistency between the data at $2 \mathrm{~Hz}$ of Figure $6 \mathrm{~B}$ and the data of Figure 5F. However, the difference between "NA" and "NA + ACh" in Figure 6B is smaller than expected from Figure $\mathbf{5 F}$, where this difference is almost significant $(P=0.06)$.

\section{CAVEATS}

In the present study, we have used the amphotericin-perforated patch-clamp technique to test the effects of noradrenalin, acetylcholine, or a combination thereof on the action potential configuration of isolated sinoatrial and atrial myocytes under close-tophysiological conditions. Whereas this approach allows a detailed study of the effects of a well-controlled dose of these neurotransmitters on the intrinsic action potential configuration of these isolated myocytes, it does not take into account the complexity and heterogeneity of the intact myocardium. Therefore, caution should be applied when translating our in vitro results to the in vivo situation. Furthermore, although human action potential morphology is better resembled by rabbit than by mouse, there may be species differences in the effects of noradrenalin and acetylcholine.

\section{CONCLUSION}

Our data show that acetylcholine and noradrenalin can modulate the beating rate of SA nodal myocytes and the action potential duration of atrial myocytes over a wide range. If specific SA nodal RGS protein isoforms exist that suppress muscarinic or adrenergic sensitivity of the SA node, they may prove therapeutical targets for the treatment of SA nodal bradycardia or tachycardia. Atrialspecific RGS protein isoforms may prove useful as therapeutical targets to increase the adrenergic sensitivity of atrial cells, thereby increasing their action potential duration and refractory period and thus decreasing the risk of atrial tachycardia and fibrillation. This will, however, require a large body of research before one can think of clinical translation.

\section{ACKNOWLEDGMENTS}

The authors wish to thank Jan G. Zegers and Dr. Antoni C. G. van Ginneken for kindly providing the data acquisition and data analysis software, respectively, and Berend de Jonge and Cees A. Schumacher for biotechnical assistance. 


\section{REFERENCES}

Abramochkin, D. V., Tapilina, S. V., Sukhova, G. S., Nikolsky, E. E., and Nurullin, L. F. (2012). Functional M3 cholinoreceptors are present in pacemaker and working myocardium of murine heart. Pflugers Arch. 463, 523-529.

Barry, P. H., and Lynch, J. W. (1991). Liquid junction potentials and small cell effects in patch clamp analysis. J. Membr. Biol. 121, 101-107.

Bean, B. P. (1985). Two kinds of calcium channels in canine atrial cells. Differences in kinetics, selectivity, and pharmacology. J. Gen. Physiol. 86, $1-30$.

Bender, K., Nasrollahzadeh, P., Timpert, M., Liu, B., Pott, L., and Kienitz, M. C. (2008). A role for RGS10 in $\beta$-adrenergic modulation of G-protein-activated $\mathrm{K}^{+}$ (GIRK) channel current in rat atrial myocytes. J. Physiol. (Lond.) 586, 2049-2060.

Boyett, M. R., Kodama, I., Honjo, H., Arai, A., Suzuki, R., and Toyama, J. (1995). Ionic basis of the chronotropic effect of acetylcholine on the rabbit sinoatrial node. Cardiovasc. Res. 29, 867-878.

Brack, K. E., Coote, J. H., and Ng, G. A. (2004). Interaction between direct sympathetic and vagus nerve stimulation on heart rate in the isolated rabbit heart. Exp. Physiol. 89, 128-139.

Brunner, M., Peng, X., Liu, G. X., Ren, X. Q., Ziv, O., Choi, B. R., Mathur, R., Hajjiri, M., Odening, K. E., Steinberg, E., Folco, E. J., Pringa, E., Centracchio, J., Macharzina, R. R., Donahay, T., Schofield, L., Rana, N., Kirk, M., Mitchell, G. F., Poppas, A., Zehender, M., and Koren, G. (2008). Mechanisms of cardiac arrhythmias and sudden death in transgenic rabbits with long QT syndrome. J. Clin. Invest. 118, 2246-2259.

Casini, S., Verkerk, A. O., van Borren, M. M. G. J., van Ginneken, A. C. G., Veldkamp, M. W., de Bakker, J. M. T., and Tan, H. L. (2009). Intracellular calcium modulation of voltagegated sodium channels in ventricular myocytes. Cardiovasc. Res. 81, 72-81.

Cifelli, C., Rose, R. A., Zhang, H., Voigtlaender-Bolz, J., Bolz, S. S., Backx, P. H., and Heximer, S. P. (2008). RGS4 regulates parasympathetic signaling and heart rate control in the sinoatrial node. Circ. Res. 103, 527-535.
Den Ruijter, H. M., Verkerk, A. O., and Coronel, R. (2010). Incorporated fish oil fatty acids prevent action potential shortening induced by circulating fish oil fatty acids. Front. Physiol. 1:149. doi:10.3389/fphys.2010.00149

DiFrancesco, D. (1995). The onset and autonomic regulation of cardiac pacemaker activity: relevance of the f current. Cardiovasc. Res. 29, 449-456.

Dun, W., Yagi, T., Rosen, M. R., and Boyden, P.A. (2003). Calcium and potassium currents in cells from adult and aged canine right atria. Cardiovasc. Res. 58, 526-534.

Ehrlich, J. R., Cha, T. J., Zhang, L., Chartier, D., Villeneuve, L., Hébert, T. E., and Nattel, S. (2004). Characterization of a hyperpolarization-activated timedependent potassium current in canine cardiomyocytes from pulmonary vein myocardial sleeves and left atrium. J. Physiol. (Lond.) 557, 583-597.

Fu, Y., Huang, X., Piao, L., Lopatin, A. N., and Neubig, R. R. (2007). Endogenous RGS proteins modulate SA and AV nodal functions in isolated heart: implications for sick sinus syndrome and AV block. Am. J. Physiol. Heart Circ. Physiol. 292, H2532-H2539.

Fu, Y., Huang, X., Zhong, H., Mortensen, R. M., D'Alecy, L. G., and Neubig, R. R. (2006). Endogenous RGS proteins and $\mathrm{G} \alpha$ subtypes differentially control muscarinic and adenosinemediated chronotropic effects. Circ. Res. 98, 659-666.

Grodner, A. S., Lahrtz, H. S., Pool, P. E., and Braunwald, E. (1970). Neurotransmitter control of sinoatrial pacemaker frequency in isolated rat atria and in intact rabbits. Circ. Res. 27, 867-873.

Hagiwara, N., Irisawa, H., and Kameyama, M. (1988). Contribution of two types of calcium currents to the pacemaker potentials of rabbit sino-atrial node cells. J. Physiol. (Lond.) 395, 233-253.

Harvey, R. D., and Belevych, A. E. (2003). Muscarinic regulation of cardiac ion channels. Br. J. Pharmacol. 139, 1074-1084.

Jahnel, U., Kaufmann, B., Rombusch, M., and Nawrath, H. (1992). Contribution of both $\alpha$ - and $\beta$-adrenoceptors to the inotropic effects of catecholamines in the rabbit heart. Naunyn Schmiedebergs Arch. Pharmacol. 346, 665-672.
Jweied, E., deTombe, P., and Buttrick, P. M. (2007). The use of human cardiac tissue in biophysical research: the risks of translation. J. Mol. Cell. Cardiol. 42, 722-726.

Kimple, A. J., Bosch, D. E., Giguère, P. M., and Siderovski, D. P. (2011). Regulators of G-protein signaling and their $\mathrm{G} \alpha$ substrates: promises and challenges in their use as drug discovery targets. Pharmacol. Rev. 63, 728-749.

Koumi, S., Sato, R., and Hayakawa, H. (1995). Characterization of the acetylcholine-sensitive muscarinic $\mathrm{K}^{+}$channel in isolated feline atrial and ventricular myocytes. J. Membr. Biol. 145, 143-150.

Levy, M. N. (1971). Sympatheticparasympathetic interactions in the heart. Circ. Res. 29, 437-445.

Mackaay, A. J. C., Op't Hof, T., Bleeker, W. K., Jongsma, H. J., and Bouman, L. N. (1980). Interaction of adrenaline and acetylcholine on cardiac pacemaker function. Functional inhomogeneity of the rabbit sinus node. J. Pharmacol. Exp. Ther. 214, 417-422.

Maltsev, V. A., and Lakatta, E. G. (2010). A novel quantitative explanation for the autonomic modulation of cardiac pacemaker cell automaticity via a dynamic system of sarcolemmal and intracellular proteins. Am. J. Physiol. Heart Circ. Physiol. 298, H2010-H2023.

Méry, P. F., Abi-Gerges, N., Vandecasteele, G., Jurevicius, J., Eschenhagen, T., and Fischmeister, R. (1997). Muscarinic regulation of the L-type calcium current in isolated cardiac myocytes. Life Sci. 60, 1113-1120.

Northover, B. J. (1994). Effect of pretreating rat atria with potassium channel blocking drugs on the electrical and mechanical responses to phenylephrine. Biochem. Pharmacol. 47, 2163-2169.

Patterson, E., Scherlag, B. J., Zhou, J., Jackman, W. M., Lazzara, R., Coscia, D., and Po, S. (2008). Antifibrillatory actions of cisatracurium: an atrial specific $\mathrm{M}_{2}$ receptor antagonist. J. Cardiovasc. Electrophysiol. 19 , 861-868.

Petit-Jacques, J., Bois, P., Bescond, J., and Lenfant, J. (1993). Mechanism of muscarinic control of the highthreshold calcium current in rabbit sino-atrial node myocytes. Pflugers Arch. 423, 21-27.

Posokhova, E., Wydeven, N., Allen, K. L., Wickman, K., and Martemyanov, K. A. (2010). RGS6/Gß5 complex accelerates $\mathrm{I}_{\mathrm{KACh}}$ gating kinetics in atrial myocytes and modulates parasympathetic regulation of heart rate. Circ. Res. 107, 1350-1354.

Shumaker, J. M., Clark, J. W., and Giles, W. R. (1991). A model of $\beta$ adrenergic effects on calcium and potassium current in bullfrog atrial myocytes. Am. J. Physiol. Heart Circ. Physiol. 261, H1937-H1944.

Sjögren, B., Blazer, L. L., and Neubig, R. R. (2010). "Regulators of G protein signaling proteins as targets for drug discovery," in Progress in Molecular Biology and Translational Science: Membrane Proteins as Drug Target, ed. C. A. Lunn (San Diego, CA: Academic Press), 81-119.

Sjögren, B., and Neubig, R. R. (2010). Thinking outside of the "RGS box": new approaches to therapeutic targeting of regulators of $\mathrm{G}$ protein signaling. Mol. Pharmacol. 78, 550-557.

Sorota, S., Rybina, I., Yamamoto, A., and $\mathrm{Du}, \mathrm{X}$. Y. (1999). Isoprenaline can activate the acetylcholine-induced $\mathrm{K}^{+}$current in canine atrial myocytes via $\mathrm{G}_{s}$-derived $\beta \gamma$ subunits. J. Physiol. (Lond.) 514, 413-423.

Tilley, D. G. (2011). G proteindependent and $G$ proteinindependent signaling pathways and their impact on cardiac function. Circ. Res. 109, 217-230.

Toda, N., and Shimamoto, K. (1968). The influence of sympathetic stimulation on transmembrane potentials in the S-A node. J. Pharmacol. Exp. Ther. 159, 298-305.

Tuomi, J. M., Chidiac, P., and Jones, D. L. (2009). Evidence for enhanced M3 muscarinic receptor function and sensitivity to atrial arrhythmia in the RGS2-deficient mouse. Am. J. Physiol. Heart Circ. Physiol. 298, H554-H561.

van Borren, M. M. G. J., Verkerk, A. O., Wilders, R., Hajji, N., Zegers, J. G., Bourier, J., Tan, H. L., Verheijck, E. E., Peters, S. L. M., Alewijnse, A. E., and Ravesloot, J. H. (2010). Effects of muscarinic receptor stimulation on $\mathrm{Ca}^{2+}$ transient, cAMP production and pacemaker frequency of rabbit sinoatrial node cells. Basic Res. Cardiol. 105, 73-87.

Veldkamp, M. W., Wilders, R., Baartscheer, A., Zegers, J. G., Bezzina, C. R., and Wilde, A. A. M (2003). Contribution of sodium channel mutations to bradycardia and sinus node dysfunction in LQT3 families. Circ. Res. 92, 976-983.

Verkerk, A. O., den Ruijter, H. M., Bourier, J., Boukens, B. J., Brouwer, I. A., Wilders, R., and Coronel, R. (2009). Dietary fish oil reduces pacemaker current and 
heart rate in rabbit. Heart Rhythm 6, 1485-1492.

Yang, J., Huang, J., Maity, B., Gao, Z., Lorca, R. A., Gudmundsson, H., Li, J., Stewart, A., Swaminathan, P. D., Ibeawuchi, S. R., Shepherd, A., Chen, C. K., Kutschke, W., Mohler, P. J., Mohapatra, D. P., Anderson, M. E., and Fisher, R. A. (2010). RGS6, a modulator of parasympathetic activation in heart. Circ. Res. 107, 1345-1349.

Yeh, Y. H., Ehrlich, J. R., Qi, X., Hébert, T. E., Chartier, D., and Nattel, S. (2007).
Adrenergic control of a constitutively active acetylcholine-regulated potassium current in canine atrial cardiomyocytes. Cardiovasc. Res. 74, 406-415.

Zhang, P., and Mende, U. (2011). Regulators of G-protein signaling in the heart and their potential as therapeutic targets. Circ. Res. 109, 320-333.

Conflict of Interest Statement: The authors declare that the research was conducted in the absence of any commercial or financial relationships that could be construed as a potential conflict of interest.

Received: 15 February 2012; paper pending published: 21 March 2012; accepted: 12 May 2012; published online: 31 May 2012.

Citation: Verkerk AO, Geuzebroek GSC, Veldkamp $M W$ and Wilders $R$ (2012) Effects of acetylcholine and noradrenalin on action potentials of isolated rabbit sinoatrial and atrial myocytes. Front. Physio. 3:174. doi: 10.3389/fphys.2012.00174

This article was submitted to Frontiers in Cardiac Electrophysiology, a specialty of Frontiers in Physiology.

Copyright () 2012 Verkerk, Geuzebroek, Veldkamp and Wilders. This is an openaccess article distributed under the terms of the Creative Commons Attribution Non Commercial License, which permits non-commercial use, distribution, and reproduction in other forums, provided the original authors and source are credited. 